\title{
Epidemiology of Sleep Disorders among Chronic Hemodialysis Patients in Senegal: A Multicentric Study
}

\author{
Zeinabou Maiga Moussa Tondi ${ }^{*}$, Sidy Mohamed Seck ${ }^{2,3}$, Elhadj Fary Ka ${ }^{4}$, \\ Mouhamadou Moustapha Cisse ${ }^{4}$, Amadou Diop Dia², Diatou Gueye Dia ${ }^{2}$, \\ Boucar Diouf ${ }^{4}$, Lamine Gueye ${ }^{3}$ \\ ${ }^{1}$ Nephrology Department, Faculty of Health Sciences, University Abdou Moumouni, Niamey, Niger \\ ${ }^{2}$ Faculty of Health Sciences, University Gaston Berger, Saint-Louis, Senegal \\ ${ }^{3}$ UMI 3189, "Environnement Santé Société UCAD", Dakar, Senegal \\ ${ }^{4}$ Nephrology Department, University Hospital HALD, Dakar, Senegal \\ Email: "zeinab_maiga@yahoo.fr
}

Received 27 October 2015; accepted 12 January 2016; published 15 January 2016

Copyright (C) 2016 by authors and Scientific Research Publishing Inc.

This work is licensed under the Creative Commons Attribution International License (CC BY). http://creativecommons.org/licenses/by/4.0/

c) (7) Open Access

\section{Abstract}

Introduction: Sleep disorders (SD) are common dialysis patients and can impact their quality of life. In previous studies, black ethnicity was associated with higher incidence of SD but a few data are available in African patients. This study aimed to describe prevalence and risk factors of SD among Senegalese dialysis patients. Methods: We performed a cross-sectional study between February $15^{\text {th }}$ and April $30^{\text {th }} 2012$ including 127 patients (75 males and 52 females) aged $46.8 \pm 16.9$ (16 - 85 years) and dialysed since $>6$ months in three dialysis centres. For each patient, we assessed insomnia according to international definition, obstructive sleep apnea syndrome (OSAS) with the Berlin questionnaire, restless leg syndrome (RLS) using abridged version of CambridgeHopkins RLS questionnaire, and excessive daytime sleepiness (EDS) with Epworth sleepiness scale. Logistic multivariate regression was used to identify factors associated with different SD. Results: Overall prevalence of SD was $88 \%$ comprising: insomnia (64.3\%), OSAS (49.1\%), RLS (24.1\%) and EDS (20.5\%). Forty-two patients presented at least two disorders. No difference was noticed in prevalence of SD between genders $(p=0.14)$. Level of blood pressure were not different across patients with and without SD. Insomnia correlated with anemia, inflammation and EDS. OSAS was associated with age $\geq 50$ years, EDS and neck circumference $\geq 25 \mathrm{~cm}$. RLS correlated with anemia and EDS. Other parameters such as gender, dialysis vintage, KT/V, obesity, diabetes status and hypoalbuminemia were not associated with the different SD. The majority of patients had not been diagnosed before the survey and none of them was under treatment. Conclusions: Our findings are

\footnotetext{
${ }^{*}$ Corresponding author.
}

How to cite this paper: Tondi, Z.M.M., Seck, S.M., Ka, E.F., Cisse, M.M., Dia, A.D., Dia, D.G., Diouf, B. and Gueye, L. (2016) Epidemiology of Sleep Disorders among Chronic Hemodialysis Patients in Senegal: A Multicentric Study. Health, 8, 42-48. http://dx.doi.org/10.4236/health.2016.81006 
compatible with high prevalence of sleep disorders reported in other populations. Insomnia and OSAS are the most frequent SD but some patients combined many disorders. Nephrologists should be more aware of these SD in order to detect them early and provide efficient treatment.

\title{
Keywords
}

\author{
Sleep Disorders, Hemodialysis, Epidemiology, Senegal
}

\section{Introduction}

Chronic kidney disease (CKD) and particularly dialysis patients are exposed to diverse sleep disorders (SD) that can impact their daily quality of life and cardiovascular prognosis [1]. Compared to general population, prevalence of SD in CKD patients is significantly higher due to the presence of usual risk factors such as age, gender, obesity and other factors peculiar to uremia and dialysis treatment (anemia, uremic toxins, inflammation, water an sodium overload, drugs side effects) [2]. In fact, sleep disorders appear very early during CKD stage 1 and 2 and might worsen with decline of renal function [2]. In dialysis patients prevalence of SD is variable and around $80 \%$ of them complain of poor sleep quality [3]. Among the different SD, insomnia, sleep apnea, restless leg syndrome (RLS), and excessive daytime sleepiness (EDS) are the most frequently reported [4]. Furthermore, studies have shown that SD might increase the risk of cardiovascular death in patients with CKD [3].

Previous studies from USA reported racial difference in incidence of SD but a few data are available in northern Africa [4]. This study aimed to describe prevalence and risk factors of four major SD among Senegalese dialysis patients.

\section{Patients and Methods}

We performed a cross-sectional study between February $15^{\text {th }}$ and April $30^{\text {th }} 2012$ including end-stage renal disease patients aged $\geq 16$ years from three dialysis centres in Senegal (02 in Dakar the capital city and 01 in Saint-Louis). Patients who were dialysed since less than 6 months were not included and all patients were asked to give their free consent to participate in the study. After inclusion, all patients were screened for the following sleep disorders: insomnia, obstructive sleep apnea, restless legs syndrome and excessive daytime sleepiness. Insomnia was defined as difficulty in falling asleep, waking up too early, or frequent awakening with difficulty in falling asleep once again, in addition to secondary daytime impairments that relate to night time sleep difficulties [5]. Risk of obstructive sleep apnea syndrome (OSAS) was estimated with the Berlin questionnaire with a positive score (high risk of OSAS) considered in patients presenting two categories or more [6]. The restless leg syndrome (RLS) was assessed by the abridged version of Cambridge-Hopkins RLS questionnaire (RLSSFDQ13) [7]. Excessive daytime sleepiness (EDS) assessed with Epworth Sleeping Scale and a score greater than 10 defined EDS [8]. Concomitantly, clinical (age, gender, medical history, tobacco and alcohol consumption, underlying kidney disease, blood pressure, temperature, dry weight), biochemical (serum creatinine, blood urea, hemoglobin, fasting glycemia, albuminemia, c-reactive protein, calcemia and phosphatemia) and dialysis parameters (frequency and duration of dialysis session, dry weight, interdialytic weight gain, mean KT/V) were collected from the patients' medical records.

Descriptive and inferential statistical analyses were done with SPSS 18.0 (Chicago, IL). Data were expressed as mean standard deviation or median inerquartile range or percent according to their nature and distribution. Prevalence of each SD was estimated. Univariate and multivariate logistic regression analysis was used to identify risk factors associated with the different disorders. Insomnia, OSAS and RLS were taken as independent dichotomous variables and a model was constructed for each of them to identify covariates associated with to each sleep disorder. Excessive daily sleepiness represents a usual consequence of and was not considered as a dependent variable in the multivariate analysis. A p value $\leq 0.05$ was considered as significant in all statistical tests.

\section{Results}

We included 127 patients (75 males and 52 females) with a mean age of $46.2 \pm 27.1$ (16 - 85 years). Mean di- 
alysis vintage was $41.4 \pm 16.5$ months ( 6 - 225 months). Table 1 shows the clinical and biochemical characteristics of patients and their dialysis parameters.

Sleep disorders were found in 112 patients (overall prevalence of 88\%) with a predominance of insomnia and obstructive sleep apnea. Figure 1 presents specific prevalence of the different sleep disorders. No difference was noticed in prevalence of SD between genders ( $84 \%$ in men versus $94 \%$ in women; $\mathrm{p}=0.14$ ). More than a third of patients (34.7\%) presented with at least two sleep disorders and the most frequent combinations were insomnia/EDS (16.1\%), OSAS/EDS (9.8\%) and RLS/insomnia (3.6\%) (see Figure 2).

Patients with insomnia presented significantly lower BMI than patients without insomnia (respectively 20.7 vs $28.3 \mathrm{~kg} / \mathrm{m}^{2}, \mathrm{p}=0.02$ ) and lower serum albumin (respectively $3.0 \mathrm{vs} 3.7 \mathrm{~g} / \mathrm{dL}$ ). Blood pressure levels were not different across patients with and without SD.

At univariate analysis (see Table 2), insomnia was correlated to anemia (OR $=1.11$ [1.07 - 3.46], $\mathrm{p}=0.04$ ), inflammation ( $\mathrm{OR}=1.29$ [1.02 - 8.33], $\mathrm{p}=0.05)$, and EDS ( $\mathrm{OR}=1.20$ [1.04 - 9.54], $\mathrm{p}=0.02)$. OSAS was associated with age $\geq 50$ years $(\mathrm{OR}=1.05[1.03-4.51], \mathrm{p}=0.01)$, neck circumference $>25 \mathrm{~cm}(\mathrm{OR}=1.37$ [1.07 5.75], $\mathrm{p}=0.01)$ and EDS (OR $=1.45$ [1.06 -11.95$], \mathrm{p}=0.01)$. Restless leg syndrome showed significant association with anemia $(\mathrm{OR}=3.02$ [1.10 - 5.84], $\mathrm{p}=0.03)$ and $\operatorname{EDS}(\mathrm{OR}=1.44$ [1.01 - 7.90], $\mathrm{p}=0.04)$.

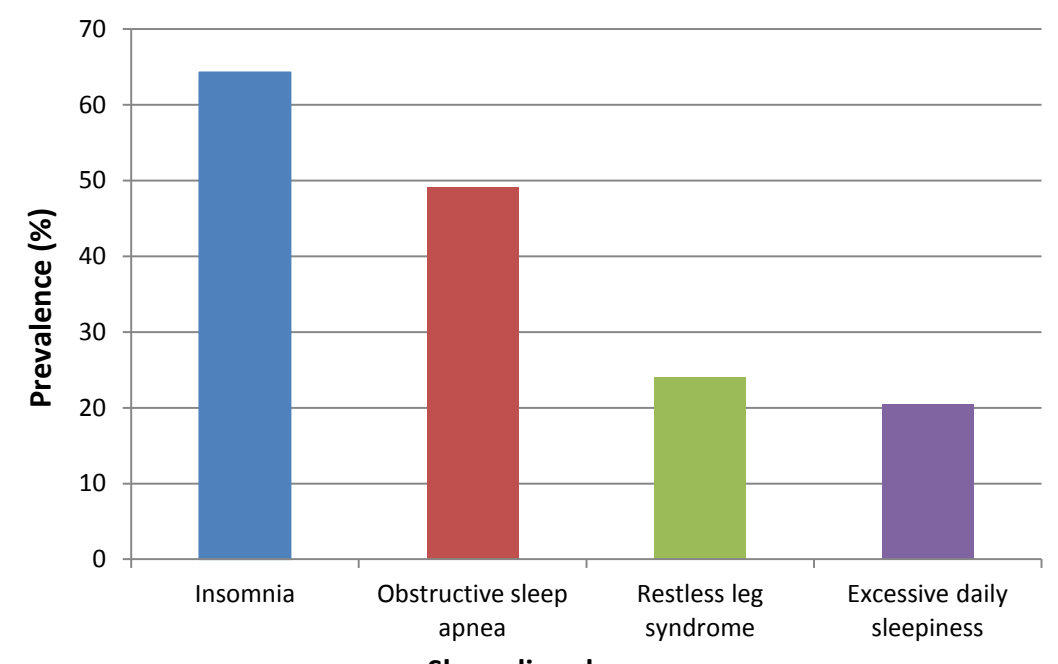

Sleep disorders

Figure 1. Prevalence of different forms of sleep disorders.

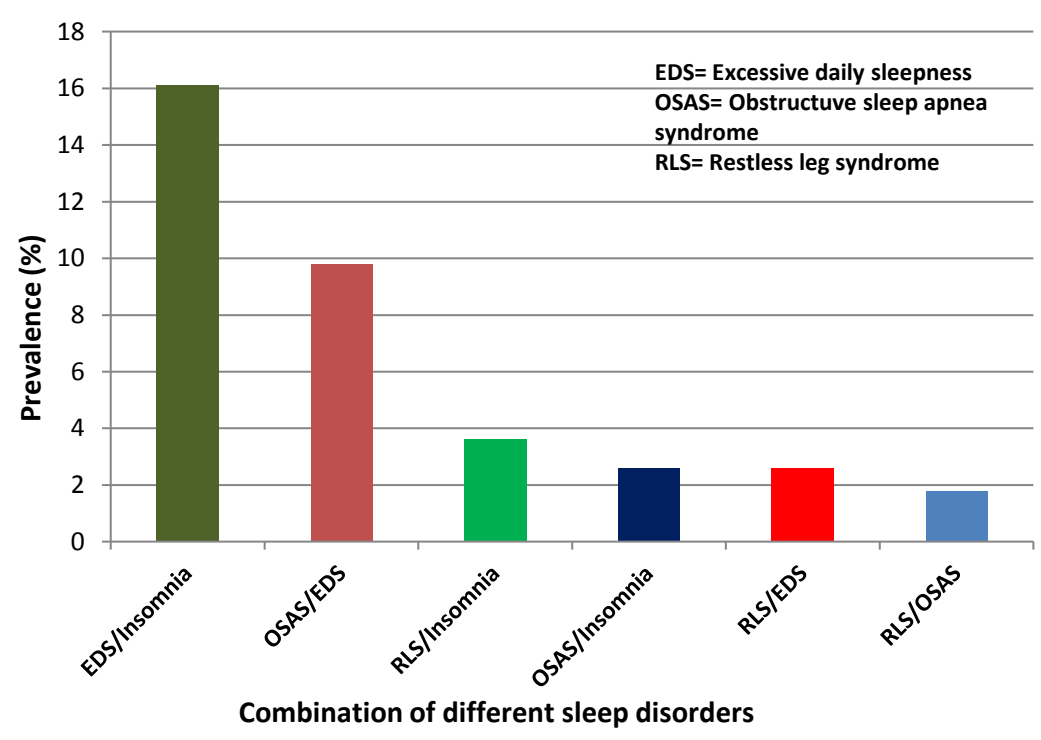

Figure 2. Association of different forms of sleep disorders. 
Table 1. Clinical and biochemical characteristic of patients.

\begin{tabular}{|c|c|c|}
\hline Parameters & Mean \pm SD & Percent \\
\hline Age (years) & $46.2 \pm 27.1(16-85)$ & \\
\hline Gender (\% male) & & $59 \%$ \\
\hline Dialysis vintage (months) & $41.4 \pm 16.5(6-125)$ & \\
\hline Dry Weight (kg) & $50.7 \pm 26.3(46-83)$ & \\
\hline Interdialytic weight gain (kg) & $1.9 \pm 2.5(0.3-3.8)$ & \\
\hline Hypertension & & $65.30 \%$ \\
\hline Diabetes & & $33.80 \%$ \\
\hline \multicolumn{3}{|l|}{ Body mass index } \\
\hline$<18.5 \mathrm{~kg} / \mathrm{m}^{2}$ & & $28.90 \%$ \\
\hline 18.5 to $25 \mathrm{~kg} / \mathrm{m}^{2}$ & & $52.90 \%$ \\
\hline$>25 \mathrm{~kg} / \mathrm{m}^{2}$ & & $18.20 \%$ \\
\hline \multicolumn{3}{|l|}{ Weekly dialysis hours } \\
\hline$\geq 12 \mathrm{~h}$ & & $64.70 \%$ \\
\hline$<12 \mathrm{~h}$ & & $34.60 \%$ \\
\hline \multicolumn{3}{|l|}{ KT/V } \\
\hline$\geq 1.2$ & & $77.20 \%$ \\
\hline$<1.2$ & & $22.80 \%$ \\
\hline C-reactive protein (mg/L) & $5.2 \pm 9.5(0.42-48.6)$ & \\
\hline Serum albumin (g/dL) & $39 \pm 25.8(18.7-46.5)$ & \\
\hline Serum hemoglobin (g/dL) & $09.5 \pm 10.2(0.63-14.8)$ & \\
\hline Phosphatemia (mg/dL) & $4.6 \pm 3.5(2.43-6.25)$ & \\
\hline Calcemia (mg/dL) & $2.1 \pm 2.6(75-106)$ & \\
\hline
\end{tabular}

Table 2. Univariate analysis of factors associated with sleep disorders.

\begin{tabular}{|c|c|c|c|c|c|c|}
\hline \multirow{2}{*}{ Variables } & \multicolumn{2}{|c|}{ Insomnia } & \multicolumn{2}{|c|}{ Sleep apnea syndrome } & \multicolumn{2}{|c|}{ Restless legs syndrome } \\
\hline & OR $[95 \% \mathrm{CI}]$ & p-value & OR $[95 \% \mathrm{CI}]$ & p-value & OR [95\% CI] & p-value \\
\hline Age $\geq 50$ years & $1.10[0.90-3.06]$ & 0.21 & $1.05[1.03-4.51]$ & 0.01 & $1.21[0.75-3.45]$ & 0.08 \\
\hline Gender (Male) & $1.13[0.26-7.94]$ & 0.67 & $1.09[0.58-4.25]$ & 0.61 & $1.16[0.51-5.52]$ & 0.49 \\
\hline Hypertension & $0.86[0.97-1.03]$ & 0.78 & $1.85[0.61-4.36]$ & 0.23 & $0.95[0.50-1.78]$ & 0.81 \\
\hline Obesity & $0.78[0.50-1.74]$ & 0.26 & $0.99[0.72-2.64]$ & 0.17 & $0.45[0.34-1.84]$ & 0.52 \\
\hline Diabetes & $1.20[0.50-4.78]$ & 0.56 & $1.23[0.15$ - 3.94] & 0.86 & $1.17[0.65-3.28]$ & 0.65 \\
\hline $\mathrm{EDS}^{\mathrm{a}}$ & $1.20[1.04-9.54]$ & 0.02 & 1.45 [1.06 - 11.95] & 0.01 & $1.44[1.01-7.90]$ & 0.04 \\
\hline Anemia & $1.11[1.07-3.46]$ & 0.04 & $1.27[0.59-7.40]$ & 0.89 & $3.02[1.10-5.84]$ & 0.03 \\
\hline Inflammation $^{\mathrm{b}}$ & $1.29[1.02-8.33]$ & 0.05 & $1.02[0.36-9.43]$ & 0.21 & $0.94[0.35-1.62]$ & 0.38 \\
\hline Hypoalbuminemia & $0.88[0.03-3.46]$ & 0.67 & $1.33[0.60-3.08]$ & 0.55 & $1.70[0.66-6.98]$ & 0.42 \\
\hline Low dialysis quality ${ }^{\mathrm{c}}$ & $1.01[0.01-10.67]$ & 0.82 & $1.05[0.38-9.45]$ & 0.35 & $1.10[0.25-15.12]$ & 0.39 \\
\hline $\mathrm{NC}^{\mathrm{d}} \geq 25 \mathrm{~cm}$ & $1.06[0.08-8.62]$ & 0.50 & $1.37[1.07-5.75]$ & 0.01 & $0.92[0.10-9.06]$ & 0.78 \\
\hline IDWG $^{\mathrm{e}} \geq 2.5 \mathrm{~kg}$ & $1.01[0.63-1.99]$ & 0.22 & $0.92[0.15-6.47]$ & 0.29 & $0.95[0.07-8.12]$ & 0.43 \\
\hline
\end{tabular}

${ }^{\mathrm{a}} \mathrm{EDS}$ = excessive daytime sleepness; ${ }^{\mathrm{b}}$ Inflammation = C-reactive protein $\geq 6 \mathrm{mg} / \mathrm{l} ;{ }^{\mathrm{c}}$ mean monthly KT/V $<1.2 ;{ }^{\mathrm{d}} \mathrm{NC}=$ neck circumference; ${ }^{\mathrm{e}} \mathrm{IDWG}=$ interdialytic weight gain. 
However, the multivariate analysis (see Table 3) identified anemia (OR $=1.31$ [1.04 - 2.76], p = 0.03), EDS $(\mathrm{OR}=1.28$ [1.02 - 5.57], $\mathrm{p}=0.02)$ and inflammation $(\mathrm{OR}=1.23$ [1.05 -4.63$], \mathrm{p}=0.01)$ as factors associated with insomnia. Neck circumference $>25 \mathrm{~cm}(\mathrm{OR}=1.25[1.02-3.62], \mathrm{p}=0.03)$, age $\geq 50$ years $(\mathrm{OR}=1.08$ [1.01 - 3.55], $\mathrm{p}=0.02)$ and EDS (OR $=1.18$ [1.02 - 8.25], $\mathrm{p}=0.02)$ were still correlated to OSAS. Also, anemia was the strongest risk factor for RLS (OR = 3.32 [1.04 - 8.33], $\mathrm{p}=0.05)$ followed by EDS $(\mathrm{OR}=1.44$ [1.05 $6.50], \mathrm{p}=0.03$ ). Other parameters such as gender, dialysis vintage, $\mathrm{KT} / \mathrm{V}$, obesity, diabetes status and hypoalbuminemia did not show significant association with any of the four studied disorders. The majority of patients were not diagnosed before the survey and none of them was under treatment.

\section{Discussion}

This study shows that sleep disorders are very common in Senegalese patients undergo dialysis. The overall prevalence of SD was even higher than what was reported in Asian or European patients, ranging from $41 \%$ to $86 \%$ [9] [10]. Insomnia which concerned more than half of our patients was also found in majority of previous studies as the most frequent disorder in dialysis patients [4]. It was correlated with anemia, EDS and inflammation. Furthermore, in comparison to general population dialysis patients are more exposed to insomnia due to other SD like OSAS or RLS and the impact in patient's daily activity can be worsened with presence of excessive sleepiness [11].

The OSAS was the second SD in our patients and its prevalence is comparable to data reported by other studies in Spain and Switzerland [12].

Other authors had found much lower prevalence in patients from Saudi Arabia (35.7\%) [13], Egypt (31.8\%) [14], Italy (23.6\%) [11], Brazil (36\%) [15], Germany (16.4\%) [15], China (14\%) [16], and USA (3.4\%) [17]. Like in our patients, the association between OSAS and neck circumference was confirmed in many previous studies [3] [12]. One of the hypotheses to explain the high prevalence of OASA in dialysis patients is fluid overload combined to metabolic acidosis for chronic obstructive SAS or uremic toxins accumulation in the case of SAS central type [18].

Restless legs syndrome and EDS were present respectively in $24.1 \%$ and $20.5 \%$ of our patients contrasting with the lower frequency of RLS described in African American patients [19]. In the literature, reported prevalence of RLS range from 6 to $80 \%$ [20]. Patients with OSAS and RLS commonly suffer from excessive sleepiness during daytime [9] [13] [21].

The main reason for the great variability in prevalence of SD between studies is related to the diagnosis methods used and the difference in the populations' characteristics. Berlin questionnaire is widely used by authors in dialysis patients but polysomnography is the gold standard for diagnosis of OSAS [3] [11] [15]. Also,

Table 3. Multivariate analysis of factors associated with sleep disorders.

\begin{tabular}{|c|c|c|c|c|c|c|c|c|c|}
\hline \multirow{2}{*}{ Variables } & \multicolumn{3}{|c|}{ Insomnia } & \multicolumn{3}{|c|}{ Sleep apnea syndrome } & \multicolumn{3}{|c|}{ Restless legs syndrome } \\
\hline & OR & [95\% CI] & p-value & OR & {$[95 \% \mathrm{CI}]$} & p-value & OR & {$[95 \% \mathrm{CI}]$} & p-value \\
\hline Age $\geq 50$ years & 1.20 & $0.59-10.76$ & 0.72 & 1.08 & $1.01-3.55$ & 0.02 & 1.13 & $0.85-9.65$ & 0.40 \\
\hline Gender (male) & 1.43 & $0.26-7.94$ & 0.64 & 1.05 & $0.45-10.20$ & 0.40 & 1.62 & $0.16-7.42$ & 0.49 \\
\hline Hypertension & 1.10 & $0.72-1.03$ & 0.91 & 1.24 & $0.82-14.51$ & 0.42 & 1.41 & $0.25-13.95$ & 0.18 \\
\hline Obesity & 0.78 & $0.50-1.22$ & 0.78 & 1.53 & $0.87-7.11$ & 0.18 & 1.02 & $0.34-2.56$ & 0.32 \\
\hline Anemia & 1.31 & $1.04-2.76$ & 0.03 & 1.45 & $0.14-6.77$ & 0.70 & 3.32 & $1.04-8.33$ & 0.05 \\
\hline Inflammation $^{\mathrm{a}}$ & 1.23 & $1.05-4.63$ & 0.01 & 1.25 & $0.68-7.25$ & 0.40 & 1.12 & $0.34-2.56$ & 0.32 \\
\hline Low dialysis quality ${ }^{\mathrm{b}}$ & 1.20 & $0.96-1.87$ & 0.47 & 0.47 & $0.24-2.68$ & 0.45 & 0.48 & $0.70-1.31$ & 0.29 \\
\hline $\mathrm{IDWG}^{\mathrm{c}} \geq 2.5 \mathrm{~kg}$ & 1.50 & $0.27-6.85$ & 0.56 & 1.04 & $0.92-3.56$ & 0.50 & 0.69 & $0.55-1.54$ & 0.88 \\
\hline $\mathrm{NC}^{\mathrm{d}} \geq 25 \mathrm{~cm}$ & 1.06 & $0.55-7.62$ & 0.23 & 1.25 & $1.02-3.62$ & 0.03 & 1.01 & $0.25-9.83$ & 0.27 \\
\hline $\mathrm{EDS}^{\mathrm{e}}$ & 1.28 & $1.02-5.57$ & 0.02 & 1.18 & $1.02-8.25$ & 0.02 & 1.44 & $1.05-6.50$ & 0.03 \\
\hline
\end{tabular}

${ }^{\mathrm{a}}$ Inflammation $=$ C-reactive protein $\geq 6 \mathrm{mg} / \mathrm{l} ;{ }^{\mathrm{b}}$ mean monthly $\mathrm{KT} / \mathrm{V}<1.2 ;{ }^{\mathrm{c}} \mathrm{IDWG}=$ interdialytic weight gain; ${ }^{\mathrm{d}} \mathrm{NC}=$ neck circumference; ${ }^{\mathrm{e}} \mathrm{EDS}=\mathrm{ex}-$ cessive daytime sleepness. 
we used an abridged version of Cambridge questionnaire which was shown to more accurate than IRLSSG questionnaire extensively studied in many countries [7].

Though many factors such as diabetes, neuropathy, uremia, psychiatric disorders, and anemia were identified as associated to SD [22] [23], the only risk factors significantly associated with sleep disorders were age (for OSAS), neck circumference (for OSAS), anemia (for insomnia, OSAS and RLS) and inflammation (for insomnia) while as EDS was correlated with all other SD.

Despite the interesting findings, our study presents many limitations due firstly to its small sample size. Moreover, assessment of sleep disorders based on questionnaires may have overestimated or underestimated the true prevalence of diseases. Finally, because of the cross-sectional design, any significant association found with regression analysis do not imply any causal effect.

However, these differences in measurement tools should not hide the potential negative impact of SD on patients'quality of life and survival [2] [12] [24].

\section{Conclusion}

This study shows that in Senegalese patients undergoing dialysis, sleep disorders are as common as reported in other populations. Insomnia and OSAS are the most frequent SD but one third of patients combined many disorders. Anemia and inflammation represent the main risk factors for insomnia and RLS while age and neck circumference $>25 \mathrm{~cm}$ are associated with OSAS. Excessive daily sleepiness is a common consequence of other SD. Nephrologists and dialysis nurses should be more aware of these diseases in order to detect them early and provide efficient treatment.

\section{References}

[1] Khalil, E.S., Mohamed, E.I., Khalil, G.I., et al. (2013) Effects of Sleep Disordered Breathing on Functional Capacity and Quality of Life in Chronic Kidney Disease Egyptian Patients. Sleep Breath, 17, 621-628. http://dx.doi.org/10.1007/s11325-012-0732-0

[2] Plantinga, L., Lee, K., Inker, L.A., et al. (2011) Association of Sleep-Related Problems with CKD in the United States, 2005-2008. American Journal Kidney Disease, 58, 554-564. http://dx.doi.org/10.1053/j.ajkd.2011.05.024

[3] Bastos, J.P., Sousa, R.B., Nepomuceno, L.A., Gutierrez-Adrianzen, O.A., et al. (2007) Sleep Disturbances in Patients on Maintenance Hemodialysis: Role of Dialysis Shift. Revista Associaçao Medica Brasileira, 53, 492-496. http://dx.doi.org/10.1590/S0104-42302007000600014

[4] Ezzat, H. and Mohab, A. (2015) Prevalence of Sleep Disorders among ESRD Patients. Renal Failure, 11, 1-7. http://dx.doi.org/10.3109/0886022x.2015.1044401

[5] Association, A.A.S.D. (1997) International Classification of Sleep Disorders, Revised: Diagnostic and Coding Manuals. American Sleep Disorders Association, Rochester.

[6] Netzer, N.C., Stoohs, R.A., Netzer, C.M., et al. (1999) Using the Berlin Questionnaire to Identify Patients at Risk for the Sleep Apnea Syndrome. Annals of Internal Medicine, 131, 485-491. http://dx.doi.org/10.7326/0003-4819-131-7-199910050-00002

[7] Gholamrezaei, A. and Saadatnia, M. (2013) Application of the Cambridge-Hopkins Diagnostic Questionnaire for Investigating Restless Legs Syndrome in Patients with Chronic Renal Failure. Sleep Medicine, 14, 225. http://dx.doi.org/10.1016/j.sleep.2012.09.002

[8] Johns, M.W. (1991) A New Method for Measuring Daytime Sleepiness: The Epworth Sleepiness Scale. Sleep, 14, 540545.

[9] Parker, K.P. (2003) Sleep Disturbances in Dialysis Patients. Sleep Medicine Review, 7, 131-143. http://dx.doi.org/10.1053/smrv.2001.0240

[10] Masoumi, M., Naini, A.E., Aghaghazvini, R., et al. (2013) Sleep Quality in Patients on Maintenance Hemodialysis and Peritoneal Dialysis. International Journal of Preventive Medicine, 4, 165-172.

[11] Merlino, G., Gigli, G.L. and Valente, M. (2008) Sleep Disturbances in Dialysis Patients. Journal of Nephrology, 21, S66-S70.

[12] Muller, M.E., Heinzer, R., Pruijm, M., et al. (2012) Troubles du sommeil chez des patients présentant une insuffisance rénale chronique. Revue Médicale Suisse, 8, 458-461.

[13] Al-Jahdali, H. (2012) Prevalence of Sleep Apnea and Excessive Day Time Sleepiness in Patients with End-Stage Renal Disease on Dialysis. Saudi Journal of Kidney Diseases and Transplantation, 23, 251-261. 
[14] Sabry, A.A., Abo-Zenah, H., Wafa, E., et al. (2010) Sleep Disorders in Hemodialysis Patients. Saudi Journal of Kidney Diseases and Transplantation, 21, 300-305.

[15] Kuhlmann, U., Becker, H.F., Birkhahn, M., et al. (2000) Sleep-Apnea in Patients with End-Stage Renal Disease and Objective Results. Clinical Nephrology, 53, 460-466.

[16] Hui, D.S., Wong, T.Y., Li, T.S., et al. (2002) Prevalence of Sleep Disturbances in Chinese Patients with End Stage Renal Failure on Maintenance Hemodialysis. Medical Sciences Monitoring, 8, CR331-CR336.

[17] Sim, J.J., Rasgon, S.A., Kujubu, D.A., et al. (2009) Sleep Apnea in Early and Advanced Chronic Kidney Disease: Kaiser Permanente Southern California Cohort. Chest, 135, 710-716. http://dx.doi.org/10.1378/chest.08-2248

[18] Elias, R.M., Chan, C.T., Paul, N., et al. (2013) Relationship of Pharyngeal Water Content and Jugular Volume with Severity of Obstructive Sleep Apnea in Renal Failure. Nephrology Dialysis and Transplantation, 28, 937-944. http://dx.doi.org/10.1093/ndt/gfs473

[19] Kutner, N.G., Zhang, R., Huang, Y., et al. (2012) Racial Differences in Restless Legs Symptoms and Serum Ferritin in an Incident Dialysis Patient Cohort. International Journal of Urology Nephrology, 44, 1825-1831. http://dx.doi.org/10.1007/s11255-011-0108-6

[20] Yazdi, Z., Sadeghniiat-Haghighi, K., Kazemifar, A.M., et al. Saudi Journal of Kidney Diseases and Transplantation, 26, 625-660.

[21] Losso, R.L., Minhoto, G.R. and Riella, M.C. (2015) Sleep Disorders in Patients with End-Stage Renal Disease Undergoing Dialysis: Comparison between Hemodialysis, Continuous Ambulatory Peritoneal Dialysis and Automated Peritoneal Dialysis. International Journal of Urology Nephrology, 47, 369-375. http://dx.doi.org/10.1007/s11255-014-0860-5

[22] Parker, K.P. (2006) Sleep and Dialysis: A Research-Based Review of the Literature. American Nephrology Nurses' Association Journal, 6, 7626-7639.

[23] Sabbatini, M., Pisani, A., Crispo, A., et al. (2002) Sleep Quality in Patients with Chronic Renal Failure: A 3-Year Longitudinal Study. Sleep Medicine, 9, 240-246. http://dx.doi.org/10.1016/j.sleep.2007.04.005

[24] Elder, S.J., Pisoni, R.L., Akizawa, T., et al. (2008) Sleep Quality Predicts Quality of Life and Mortality Risk in Haemodialysis Patients: Results from the Dialysis Outcomes and Practice Patterns Study (DOPPS). Nephrology Dialysis and Transplantation, 23, 998-1004. http://dx.doi.org/10.1093/ndt/gfm630 